\title{
Probability Density Function of EMG Signals based on Hand Movements in Time and Frequency Domain
}

\author{
Ramanpreet Kaur \\ PG Student, \\ Dept. electronics and communication engineering, \\ Chandigarh university, \\ Gharuan, Punjab, India 140413
}

\author{
Payal Patial \\ Assistant Professor \\ Dept. electronics and communication engineering, \\ Chandigarh university, \\ Gharuan, Punjab, India 140413
}

\begin{abstract}
This paper attempts to estimate the probability density function of hand movements by using EMG signals. Several hand grasps generated from different hand movements, we have analyzed Tip and Lateral. Four well known pdf functions for good fitness of test are Log Logistics (3P), Johnson, Dagum (4P) and Burr (4P), that have been tested. The probability density function has been carried out in time domain and FFT domain as well as in DWT domain. It was observed that there are different distributions for different hand movements, which describe the samples most accurately with the movements of hand with respect to two channels; channel 1 and channel 2 . In this scenario, channels 1 is placed on upper limb and channel 2 placed on lower limbs as a reference channel. Although, Burr distribution and Log logistic distribution along with that Dagum has been a good fit for most of the data, it is shown in this paper that Non Negative distribution (Dagum (4P) and Burr (4P) distribution) is a better choice for estimating the Tip and Lateral hand movements.
\end{abstract}

\section{General Terms}

This method is used for classification purpose. This is the another method of classification of data set in probability density function. This is used as a clinic/ engineering field as a designing of prosthetic arm and hand.

\section{Keywords}

EMG signals hand movements' data, probability density function, and FFT, DWT, (Non- Negative distribution) Dagum or Burr distribution.

\section{INTRODUCTION}

Electromyography signals are measures of the electrical activity which is produced by muscle contraction. The produced signals are represented as a function of time and frequency. EMG signals have a variety of applications. It is used as a diagnostics tool for neuromuscular diseases, as a research tool for studying kinesiology and as control signals for prosthetic devices. EMG signals are important for hand movement's classification due to the distinct signature of each movement on the processed signal [2]. The EMG signals for hand grasps are classified into different categories. Such as Tip, Lateral, Spherical, Cylindrical, Hold, Palmar. The error performance amongst these are high in tip and lateral movements. The classification of such signals can be done by using different methods. But in this paper we have estimated the Probability Density Function for tip and lateral hand movement's to find out which distribution is best fit for the same. From this paper we get to know that Distribution is good technique to classify the EMG signals (that are includes in bio signals).

Bio signals [1] refers to collective electrical signals that are acquired from physical variable of interest. From the physical variable of interest, the nervous system controls the muscles contraction and relaxation. The signal acquired from muscles can be detected using biosensors [2], which are biometrics tools. The core part of these human-robot interfaces is a pattern classification process, where motions or intentions of motions are classified according to features extracted from EMG signals. Commands for device control are then generated from the classified motions. A variety of methods have been applied to motion classification. Common timedomain features that are extracted include the EMG mean absolute value (MAV), signal length and zero crossing rates [3]. Frequency-domain features have also been used, i.e., the coefficients of autoregressive power spectral modeling of the EMG [4]. For each movement the subject was asked to perform it for six seconds and the whole procedure was repeated 30 times for each basic movement. The data was collected using the National Instrument's (NI) Lab view [5] as a programming kernel. The earliest work can be attributed on both male and female in time and frequency domain. The signal was acquired from two Differential EMG Sensors and the signals were transmitted to a 2-channel EMG system by Delsys BagnoliтM Handheld EMG Systems [6]. This in turn, makes it important to have a reasonable approximation for the Probability Density Function of hand movements for EMG signals. DWT is a multi-resolution technique that offers localization both in time and frequency [7]. It exhibits good frequency resolution at low frequencies and good time resolution at high frequencies. Moreover, it offers the advantages of low computational cost and ease of implementation. DWT is chosen to extract features from the EMG signal. For analyzing non stationary or nonlinear signals EMD tool box was used [8]. In [9], eight popular features(Integrated Electromyogram (IEMG), zero-crossing, Slope Sign Changes, waveform length, Willison amplitude, variance, skewness and kurtosis) [10] were extracted, not only from the original EMG signals but from the three IMFs that were produced after processing the EMG signals with the help of EMD toolbox [11]. This paper tackles the identification of basic hand movements using surface-EMG-data based on an advanced signal processing technique, i.e.; pdf.

This paper has been organized into five sections. The first section describes the introduction about bio signals and EMG signal. The second section describes the results from the time domain, third section describes the results of Fast Fourier transform (FFT) and the fourth section describes the results of Discrete Wavelet transform (DWT). This paper shows the 
summarization of the distribution for all channels taken from different factors. In the last section, conclusions are summarized. The distribution of goodness of fit test for all three domains was carried out by using probability density function.

\section{ESTIMATION IN THE TIME DOMAIN 2.1 DATA DISCRIPTION}

The present study has been done on two movements, Tip and Lateral based on hand grasp. The term 'hand grasp' is used here for grasping different objects like glass, ball, ATM card and bottle. The data set that has been used in this paper was collected from five healthy subjects i.e.; from 2 females and 2 males. Two movements from each of the following hand grasps have been studied for the PDF task:

(i) For holding small tools (TIP)

(ii) For holding thin and flat objects (LATERAL)

Each movement is characterized by two channels, which gives us different value at different instances of time, and in turn is defined by movement.

\subsection{GOODNESS OF FIT TEST}

Each movement was divided into blocks of $10 \mathrm{~ms}$ and the samples (sampled from $10 \mathrm{~ms}$ blocks with frequency 44100 $\mathrm{Hz}$ ) in the time domain were subjected to Chi-squared, Anderson Darling, and Kolmogorov-Smirnov tests. For the above mentioned tests, four distributions viz. Log Logistic, Johnson, Dagum (4P), and Burr (4P) were chosen as hypothesis.

It was observed that for all the hand grasps with two movements of each, Burr(4P) and Dagum (4P) have been the best fitting distributions for TIP as well as LATERAL movements. The histogram plots in time domain have been depicted in figs 2(a)-2(d) for TIP hand grasp carried out on female 1 , female 2 , female 3 , male 1 , Male2.

$$
\begin{aligned}
& \text { The pdf of burr 4P is given by: } \\
& \qquad f(x)=\frac{\alpha k(x / \beta)^{\alpha-1}}{\beta\left(1+(x / \beta)^{\alpha)}\right)^{k+1}}
\end{aligned}
$$

The best fitting curves shown in graphs:

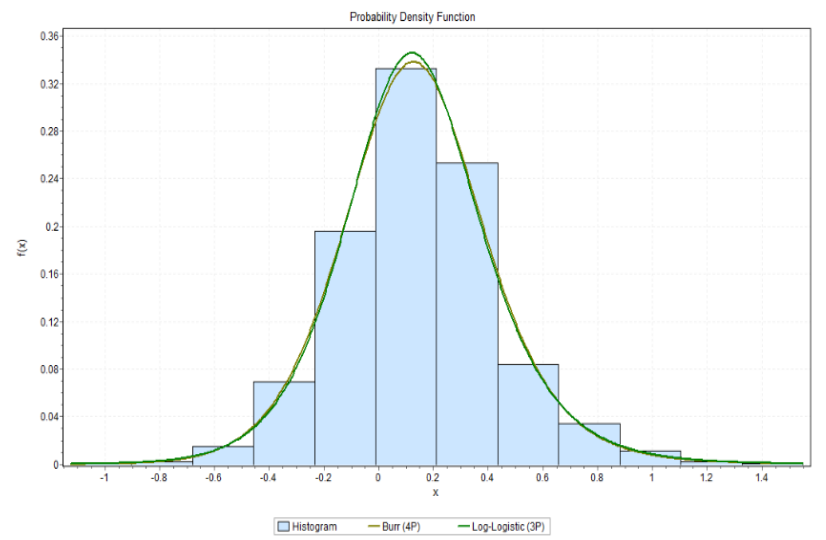

2(a)

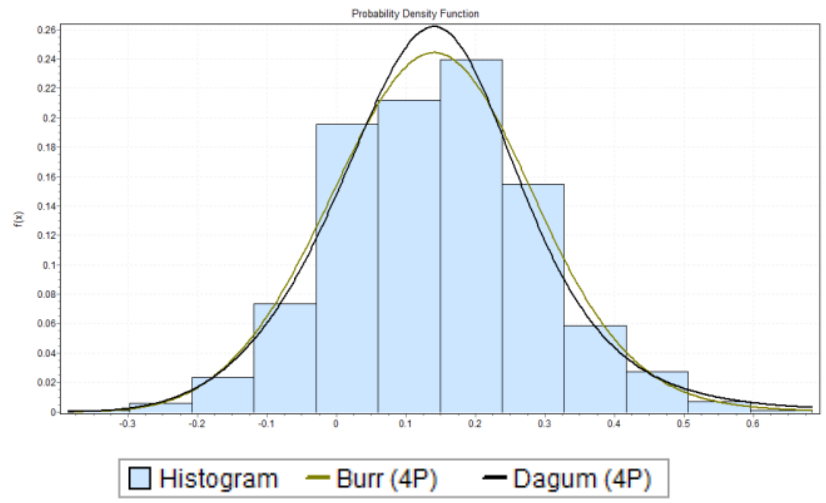

2(b)

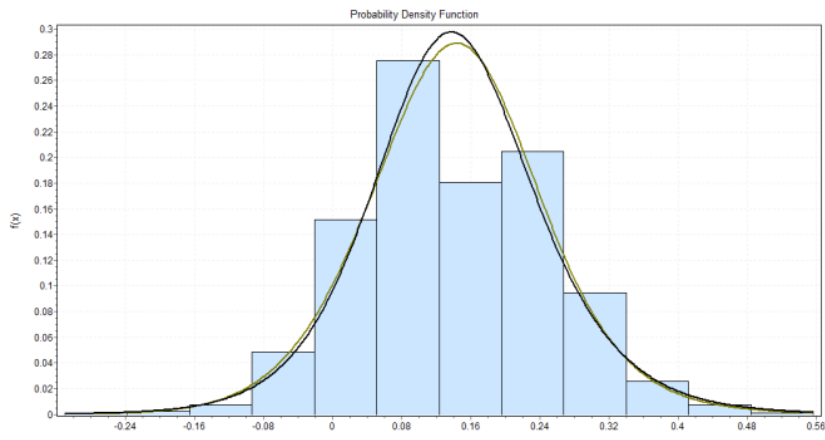

2(c)

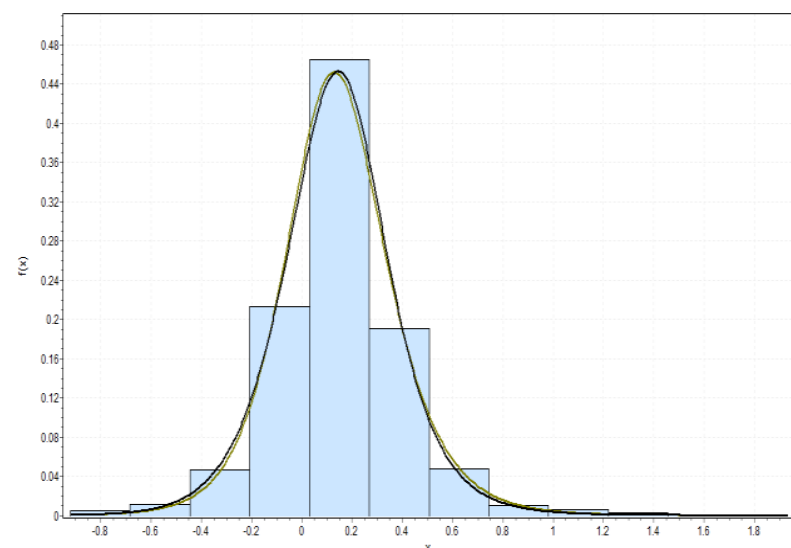

2(d)

Fig.2. Histogram Plots and Best Fitting Curves for Time Domain Samples of TIP movements (a) female 1 (b) female 2(c) male $1^{`}$ (d) male 2

The histogram plots for LATERAL hand grasps in time domain have been depicted in figs 3(a)-3(d). These histogram plots have best distribution fitting for channel1 and channel2. The best goodness of fit test is being described through these histogram plots in time domain for TIP and LATERAL movements. 


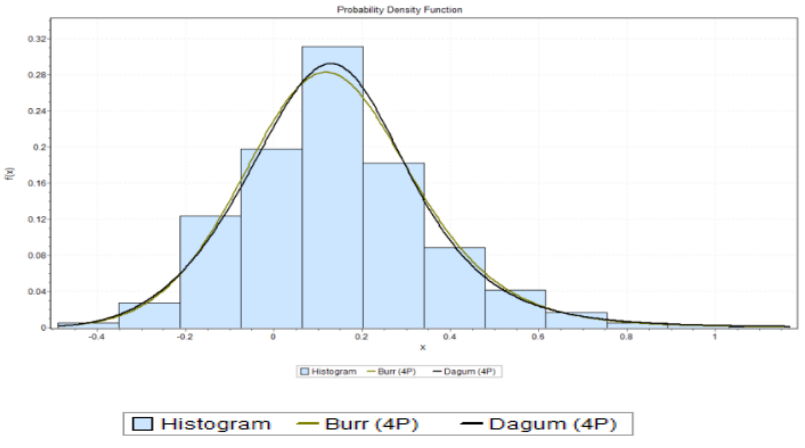

3(a)

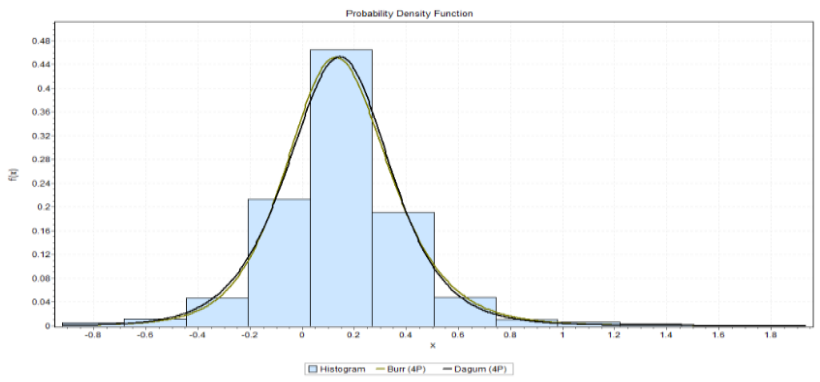

3(b)

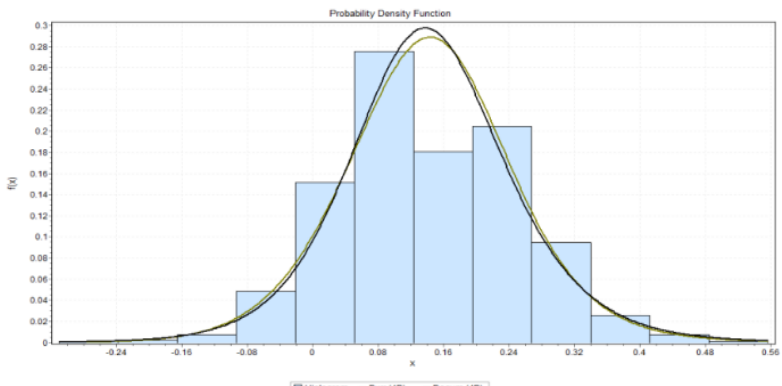

3(c)

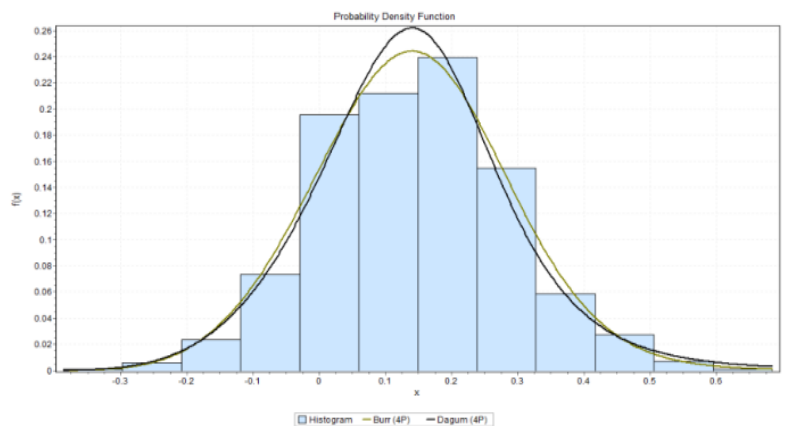

3(d)

Fig.3. Histogram Plots and Best Fitting Curves for Time Domain Samples of LATERAL movements (a) female 1 (b) female 2(c) male 1 (d) male 2

Both the distributions fitted the data slightly better than each another. The results are shown in TABLE I in which the test statistic is shown against a particular gender and a particular test. However, a better fitting Burr (4P) distribution in sometimes can be a good alternative for hand movements EMG signals.
TABLE 1.

GOODNESS OF FIT TEST IN TIME DOMAIN

\begin{tabular}{|l|l|l|l|l|}
\hline S.NO & Distribution & $\begin{array}{l}\text { Kolmogorov } \\
\text { Simonov }\end{array}$ & $\begin{array}{l}\text { Anderson } \\
\text { Darling }\end{array}$ & $\begin{array}{l}\text { Chi } \\
\text { squared }\end{array}$ \\
\hline
\end{tabular}

1. TIP

\begin{tabular}{|l|l|l|l|l|}
\hline $\begin{array}{l}\text { Female1 } \\
\text { Channel1\&2 }\end{array}$ & Burr 4P & 0.02905 & 1.4074 & 80.93 \\
\cline { 2 - 5 } & Dagum 4P & 0.03053 & 1.5197 & 27.106 \\
\hline $\begin{array}{l}\text { Female2 } \\
\text { Channel1\&2 }\end{array}$ & Burr 4P & 0.05553 & 8.0442 & 135.96 \\
\cline { 2 - 5 } & Dagum 4P & 0.05883 & 10.925 & 159.04 \\
\hline $\begin{array}{l}\text { Male 1 } \\
\text { Channel1\&2 }\end{array}$ & Burr 4P & 0.06751 & 7.5392 & 232.37 \\
\cline { 2 - 5 } & Dagum 4P & 0.0654 & 11.79 & 134.34 \\
\hline $\begin{array}{l}\text { Male 2 } \\
\text { Channel1\&2 }\end{array}$ & Burr 4p & 0.05375 & 8.2505 & 454.3 \\
\cline { 2 - 5 } & Dagum 4P & 0.05199 & 7.6438 & 486.62 \\
& & & & \\
\hline
\end{tabular}

2. LATERAL

\begin{tabular}{|l|l|l|l|l|}
\hline $\begin{array}{l}\text { Female1 } \\
\text { Channel1\&2 }\end{array}$ & Dagum 4P & 0.03322 & 2.4535 & 184.71 \\
\cline { 2 - 5 } & Burr 4P & 0.3715 & 2.2731 & 196.51 \\
\hline $\begin{array}{l}\text { Female 2 } \\
\text { Channel1\&2 }\end{array}$ & Dagum 4P & 0.06292 & 8.6377 & 239.72 \\
\cline { 2 - 5 } & Burr 4P & 0.0624 & 9.3605 & 191.57 \\
\hline $\begin{array}{l}\text { Male 1 } \\
\text { Channel1\&2 }\end{array}$ & Dagum 4P & 0.0572 & 7.2479 & 282.69 \\
\cline { 2 - 5 } & Burr 4P & 0.0599 & 5.4725 & 217.34 \\
\hline $\begin{array}{l}\text { Male 2 } \\
\text { Channel1\&2 }\end{array}$ & Dagum 4P & 0.04772 & 4.9449 & 167.32 \\
\cline { 2 - 5 } & Burr 4P & 0.04439 & 4.9272 & 186.01 \\
& & & & \\
\hline
\end{tabular}

\section{ESTIMATION IN FFT DOMAIN}

Since, most of the information content of the signal is supposed to be concentrated in tails, corresponding with lower frequencies, it is required that only significant transform components be used for the study. The nature of distribution is heavy tailed with a high kurtosis and a little skew in most of the cases. The same tests reported in the previous section have now been performed on FFT coefficients of each hand grasps. 
The histogram plots for TIP hand grasps in frequency domain (FFT) have been depicted in figs 4(a)-4(d). These histogram plots have the best distribution fitting for TIP movements are Dagum (4P) and Dagum. The histogram plots for LATERAL hand grasps in frequency domain FFT have been depicted in figs 5(a)-5(d).These histogram plots have best fitting distribution for LATERAL movements are Dagum and Burr.

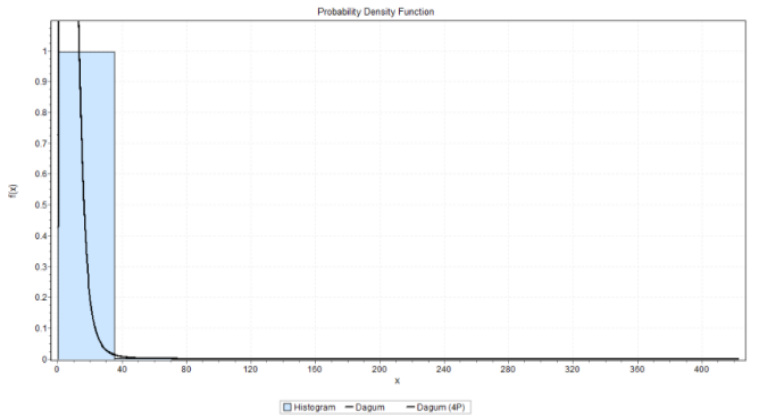

4(a)

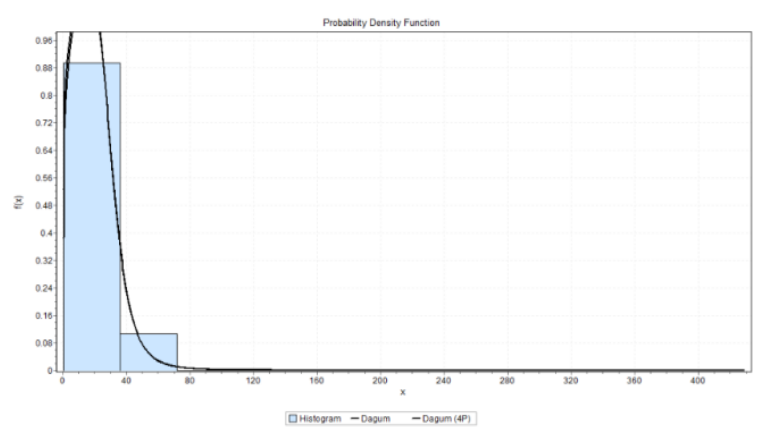

4(b)

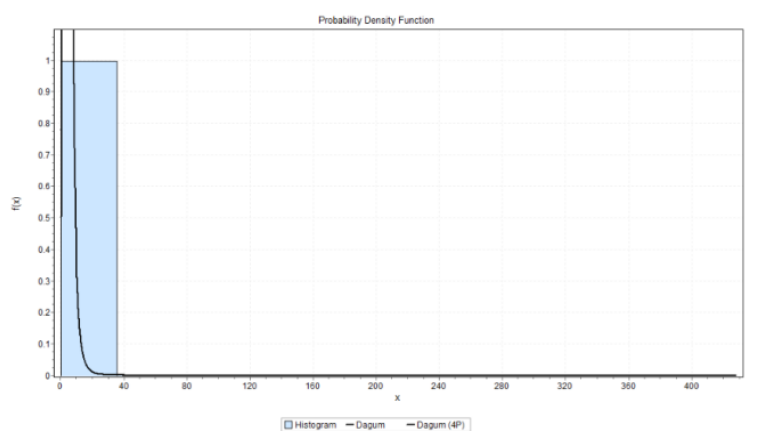

4(c)

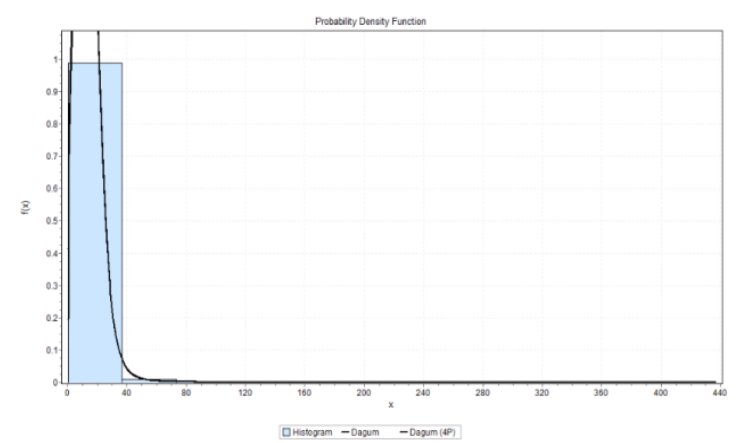

4(d)

Fig.4. Histogram Plots and Best Fitting Curves for FFT Coefficients for tip movements (a) female1 (b)female2(c)male1(d)male2

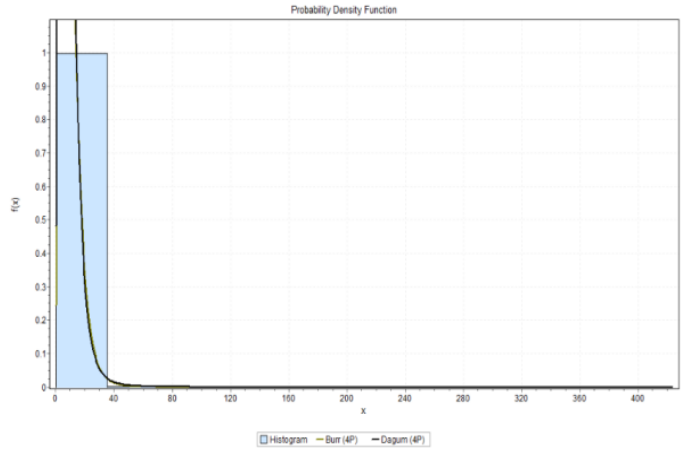

5(a)

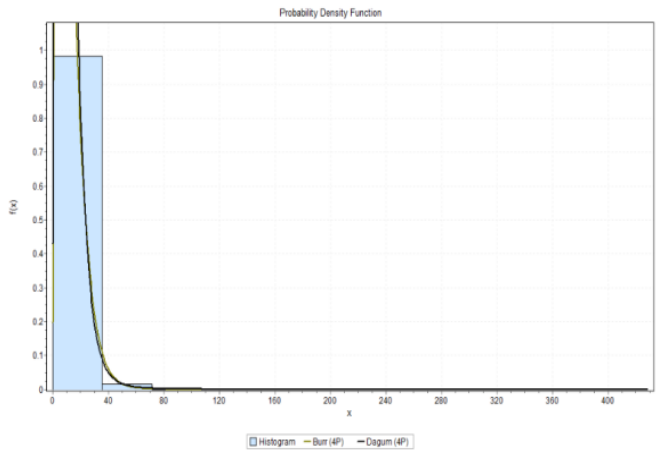

5(b)

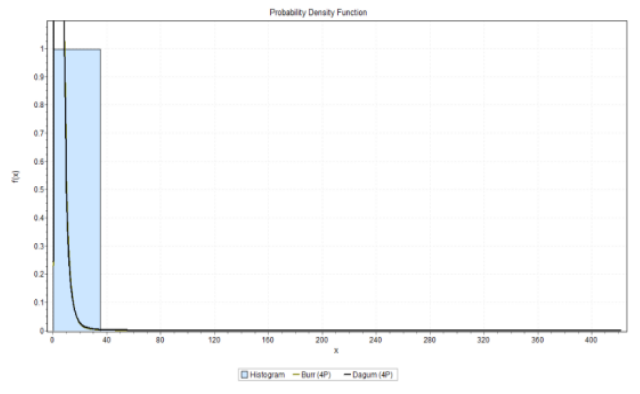

5(c)

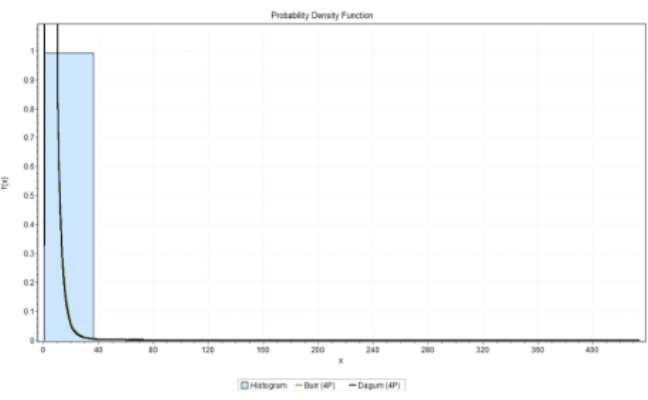

5(d)

Fig.5. Histogram Plots and Best Fitting Curves for FFT Coefficients for lateral movements (a) female1 (b)female2(c)male1(d)malle2 
Table 2. Goodness of fit test in FFT domain

\begin{tabular}{|c|c|c|c|c|}
\hline s.no & Distribution & $\begin{array}{l}\text { Kolmogorov } \\
\text { simrov }\end{array}$ & $\begin{array}{l}\text { Anderson } \\
\text { darling }\end{array}$ & $\begin{array}{l}\text { Chi- } \\
\text { squared }\end{array}$ \\
\hline \multicolumn{5}{|c|}{ 1. TIP } \\
\hline \multirow{2}{*}{$\begin{array}{l}\text { Female1 } \\
\text { Channel1\&2 }\end{array}$} & Dagum 4P & 0.01461 & 0.82285 & 21.933 \\
\hline & Dagum & 0.01595 & 1.0699 & 23.022 \\
\hline \multirow{2}{*}{$\begin{array}{l}\text { Female } 2 \\
\text { Channel1\&2 }\end{array}$} & Dagum 4P & 0.02654 & 1.8486 & 23.915 \\
\hline & Dagum & 0.02752 & 2.2839 & 21.96 \\
\hline \multirow{2}{*}{$\begin{array}{l}\text { Male1 } \\
\text { channel1\&2 }\end{array}$} & Dagum 4P & 0.01771 & 1.4687 & 27.133 \\
\hline & Dagum & 0.01952 & 1.6886 & 28.763 \\
\hline \multirow{2}{*}{$\begin{array}{l}\text { Male2 } \\
\text { Channel1\&2 }\end{array}$} & Dagum 4P & 0.01688 & 1.1907 & 28.741 \\
\hline & Dagum & 0.02256 & 1.9484 & 29.419 \\
\hline \multicolumn{5}{|c|}{ 2. LATERAL } \\
\hline \multirow{2}{*}{$\begin{array}{l}\text { Female1 } \\
\text { Channel1\&2 }\end{array}$} & Dagum 4P & 0.01892 & 1.9301 & 35.296 \\
\hline & Burr 4P & 0.01925 & 1.494 & 31.363 \\
\hline \multirow{2}{*}{$\begin{array}{l}\text { Female2 } \\
\text { Channel1\&2 }\end{array}$} & Dagum 4P & 0.0167 & 1.2122 & 20.205 \\
\hline & Burr 4P & 0.02409 & 3.2674 & 58.045 \\
\hline \multirow{2}{*}{$\begin{array}{l}\text { Male1 } \\
\text { Channel1\&2 }\end{array}$} & Dagum 4P & 0.02099 & 1.7644 & 51.816 \\
\hline & Burr 4P & 0.02125 & 1.9626 & 37.674 \\
\hline \multirow{2}{*}{$\begin{array}{l}\text { Male2 } \\
\text { Channel1\&2 }\end{array}$} & Dagum 4P & 0.02275 & 2.2093 & 28.053 \\
\hline & Burr 4P & 0.03191 & 5.8819 & 66.413 \\
\hline
\end{tabular}

The goodness of fit test is shown in Table 2 for FFT domain. This table shows that the Dagum $4 \mathrm{P}$ is best distribution in FFTgiven by domain.

The PDF of Dagum4P is:

$$
f(x)=\frac{\alpha k(x / \beta)^{\alpha k-1}}{\beta\left(1+(x / \beta)^{\alpha)}\right)^{k+1}}
$$

\section{ESTIMATION IN DWT DOMAIN}

The same tests reported in the previous section have now been performed on DWT coefficients of each hand grasps. Distribution fitting for channell and channel 2 and the best distribution fitting for TIP movements are Burr (4P) and Loglogistic 3P.

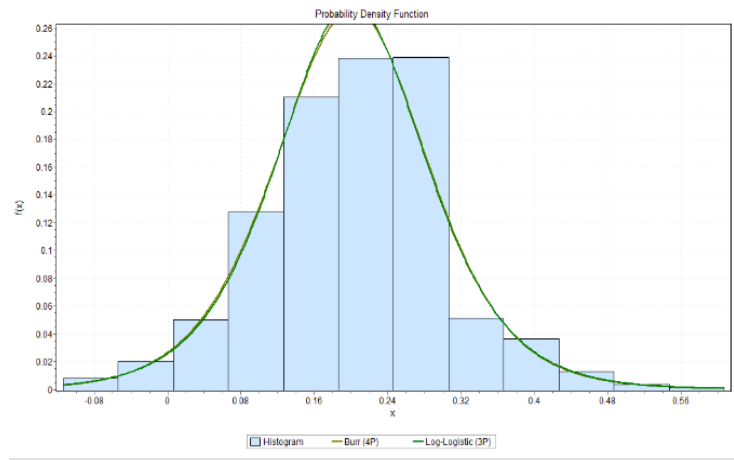

6(a)

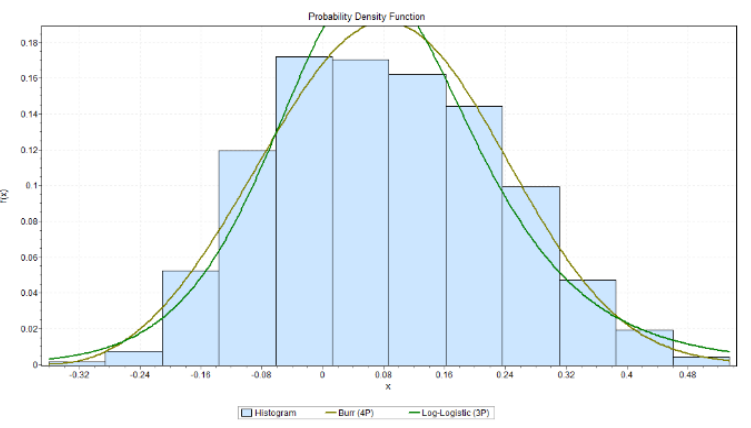

6(b)

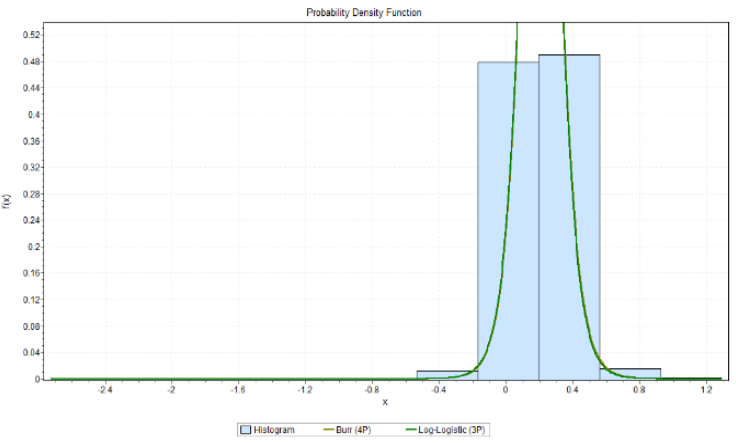

6(c)

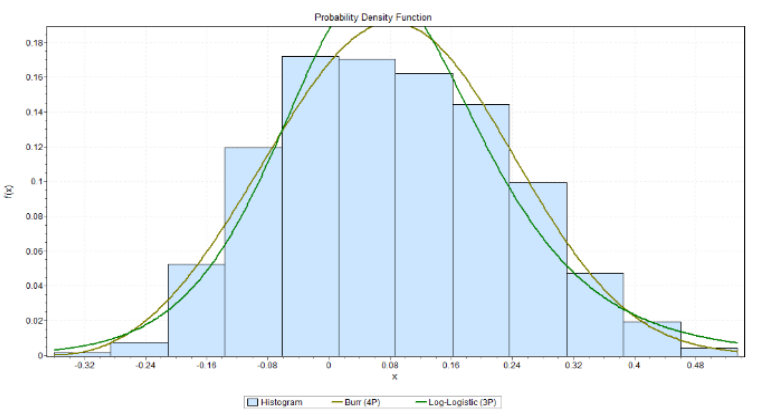

6(d)

Fig.6. Histogram Plots and Best Fitting Curves for DWT Coefficients for tip movements (a) female1 (b) female2(c) male1 (d) male2 
The histogram plots for LATERAL hand grasps in frequency domain (DWT) have been depicted in figs 7(a)-7(d).

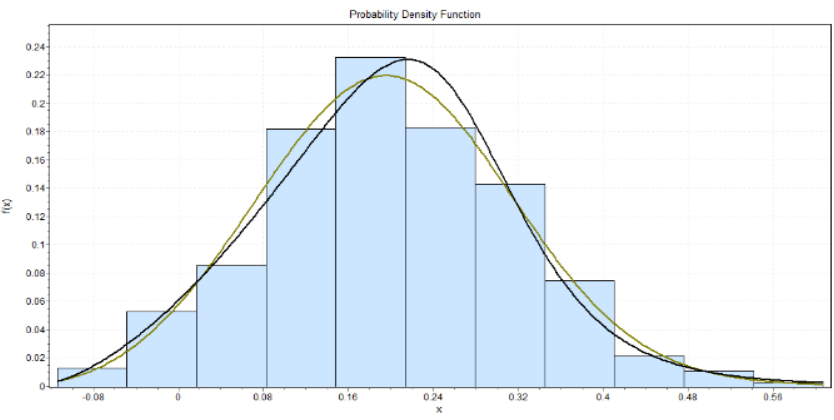

$7(\mathbf{a})$

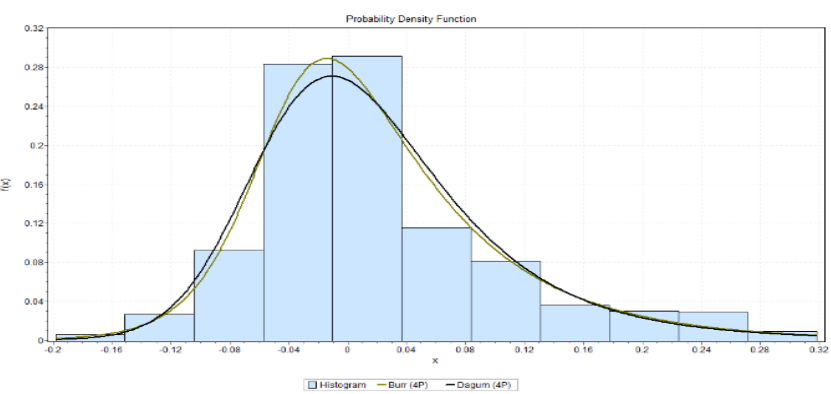

7(b)

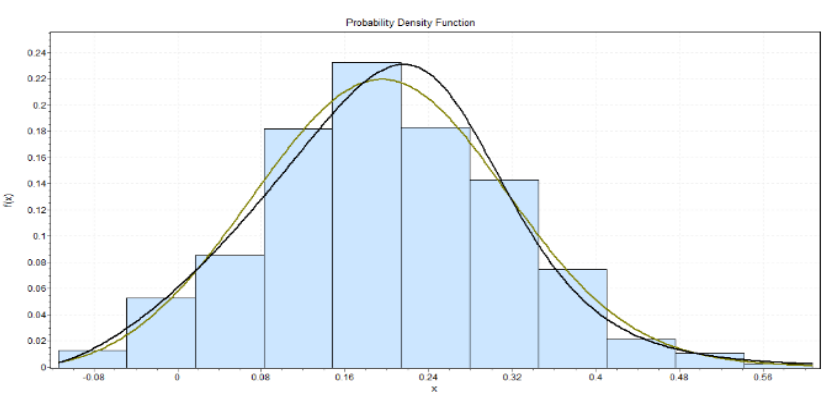

$7(\mathbf{c})$

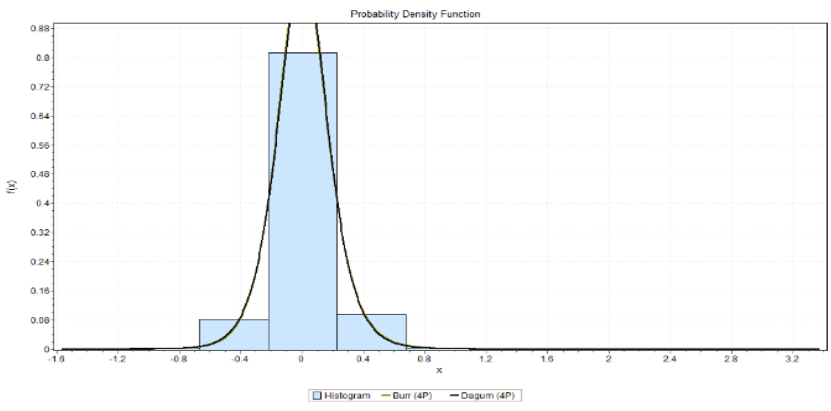

$7(d)$

Fig.7. Histogram Plots and Best Fitting Curves for DWT Coefficients for LATERAL movements (a) female1 (b) female2(c) male1 (d) male

\section{Table 3. Goodness of Fit Test in DWT Domain}

\begin{tabular}{|c|c|c|c|c|}
\hline S. No. & Distribution & $\begin{array}{l}\text { Kolmogorov } \\
\text { simrov }\end{array}$ & $\begin{array}{l}\text { Anderson } \\
\text { darling }\end{array}$ & $\begin{array}{l}\text { Chi- } \\
\text { squared }\end{array}$ \\
\hline \multicolumn{5}{|c|}{ 1. TIP } \\
\hline \multirow{2}{*}{$\begin{array}{l}\text { Female1 } \\
\text { Channel\&2 }\end{array}$} & Burr 4P & 0.03184 & 1.3025 & 68.688 \\
\hline & $\begin{array}{l}\text { Log- } \\
\text { logistic 3P }\end{array}$ & 0.03196 & 1.3208 & 68.689 \\
\hline \multirow{2}{*}{$\begin{array}{l}\text { Female2 } \\
\text { Channel1\&2 }\end{array}$} & Burr 4P & 0.04844 & 5.9389 & 168.3 \\
\hline & $\begin{array}{l}\text { Log- } \\
\text { logistic3P }\end{array}$ & 0.04898 & 5.9152 & 168.3 \\
\hline \multirow{2}{*}{$\begin{array}{l}\text { Male1 } \\
\text { Channel1\&2 }\end{array}$} & Burr4P & 0.05046 & 4.9013 & 23.202 \\
\hline & $\begin{array}{l}\text { Log- } \\
\text { logistic3P }\end{array}$ & 0.06537 & 9.8308 & 166.61 \\
\hline \multirow{2}{*}{$\begin{array}{l}\text { Male2 } \\
\text { Channel1\&2 }\end{array}$} & Burr 4P & 0.07824 & 15.335 & 162.07 \\
\hline & $\begin{array}{l}\text { Log- } \\
\text { logistic3P }\end{array}$ & 0.07801 & 12.589 & 102.07 \\
\hline
\end{tabular}

2. LATERAL

\begin{tabular}{|l|l|l|l|l|}
\hline $\begin{array}{l}\text { Female1 } \\
\text { Channel1\&2 }\end{array}$ & Dagum 4P & 0.0361 & 1.7351 & 76.018 \\
\cline { 2 - 5 } & Burr 4P & 0.03382 & 1.7015 & 97.213 \\
\hline $\begin{array}{l}\text { Female2 } \\
\text { Channel1\&2 }\end{array}$ & Dagum 4P & 0.05685 & 5.614 & 204.58 \\
\cline { 2 - 5 } & Burr 4P & 0.05911 & 5.1704 & 121.21 \\
\hline $\begin{array}{l}\text { Male1 } \\
\text { Channel1\&2 }\end{array}$ & Dagum 4P & 0.04262 & 1.9982 & 104.89 \\
\cline { 2 - 5 } & Burr 4P & 0.04256 & 2.0279 & 104.55 \\
\hline $\begin{array}{l}\text { Male2 } \\
\text { Channel1\&2 }\end{array}$ & Dagum 4P & 0.03292 & 2.4785 & 35.098 \\
\cline { 2 - 5 } & Burr 4P & 0.03249 & 2.3993 & 48.668 \\
& & & & \\
\hline
\end{tabular}

In these, best distributions are Dagum 4P and burr 4P.The goodness of fit test shown in Table

$$
f(x)=\frac{\alpha k(x / \beta)^{\alpha-1}}{\beta\left(1+(x / \beta)^{\alpha)}\right)^{k+1}}
$$

\section{CONCLUSION}

This paper brings further insight into the study of probability density function of EMG signals by estimating the distribution of movements belonging with different hand grasps. It was observed during the study that Burr $4 \mathrm{P}$ distribution in the time 
and FFT domain and in DWT domain could be an alternative for the Dagum distribution which has been the most preferred one for the estimation of movements. However, no particular relation of the distribution properties with hand grasps of EMG signals was found with the present analysis. It can also be concluded from this study that Dagum4P and Burr $4 \mathrm{P}$ distributions are best fitting test of goodness in time domain and also in frequency domain. However, there is a lot of scope to introduce some new distributions particularly suited to grasp analysis and estimation of tip and lateral movements which could go a long way in building more efficient classification systems. Since, there is no misclassification system for hand moments yet. Thus, there are further more methods which can be introduced for goodness of fit test. Due to this classification this method is used in a clinic/ biomedical engineering for designing of prosthetic arm and hand. This is suitable in future for those who has lose their control ability of hand correctly, this method is useful.

\section{REFERENCES}

[1] E. Kaniusas. "Fundamentals of Bio signals" Biomedical Signals and Sensors I, pp. 1-26, 2012.

[2] D. Carroll, A. Subbiah, "Recent Advances in Biosensors and Bio sensing Protocols"Journal of Biosensors \& Bioelectronics 2012.

[3] B. Hudgins, P. Parker, and R. N. Scott, "A new strategy for multifunction myoelectric control," IEEE Trans. Biomed Eng., vol. 40, no. 1, pp 82-94, Jan. 1993.

[4] LabVIEW System Design Software http://www.ni.com/labview/
[5] Bagnoli Handheld EMG Systems http://www.delsys.com/products/bagnoli_handheld.html

[6] N. E. Huang, Z. Shen, S. R. Long, M. L.Wu, H. H. Shih, Q. Zheng, N.C. Yen, C. C. Tung, and H. H. Liu, "The empirical mode decomposition and Hilbert spectrum For nonlinear and non-stationary time series analysis," in Proc. of the Royal Society London A, vol.454, pp. 903995, 1998.

[7] C. Sapsanis, G. Georgoulas, A. Tzes, "Improving EMG based Classification of basic hand movements using EMD" in 35th Annual International Conference of the IEEE Engineering in Medicine and Biology Society '13, Osaka, Japan, July 2013.

[8] D. Joshi, K. Kandpal, and S. Anand. "Feature evaluation to reduce false triggering in threshold based emg prosthetic hand." International Conference on Biomedical Engineering, pp. 769-772, 2008.

[9] The

EMD toolbox

<http://perso.enslyon.fr/patrick.flandrin/emd.html>

[10] K. Englehart, B. Hudgins, and A. Philip, "A waveletbased continuous classification scheme for multifunction myoelectric control," IEEE Trans. Biomed. Eng., vol. 48, no. 3, pp. 302-311, 2001.

[11] D. Graupe and W.K.Cline,"functional separation of EMG signals by ARMA identification of hand movements IEEE Trans. Sys. Man. Cyber. Vol. 5, no. 2, pp. 252-259. Apr. 1975. 